\title{
Environmental and Occupational Health Problems of Child Labour: Some Issues and Challenges for Future
}

\author{
Surendra Kumar Yadav and Gowri Sengupta* \\ Department of Environment Management, Institute of Environment Management \& Plant \\ Sciences, Vikram University, Ujjain, Madhya Pradesh, India \\ Email: sk_yadav11043@yahoo.com \\ *Department of Community Medicine, Vardhaman Medical College, \\ Safdurjung Hospital Campus, New Delhi, India \\ E-mail: gowri72@yahoo.com
}

KEYWORDS Child Labor. Environmental and Occupational Health. Developing Countries

\begin{abstract}
The relationships between child labour and health are complex. They can be direct and indirect, static and dynamic, positive and negative, causal and spurious. There is epidemiological evidence of greater impact of some occupational exposures on child health as compared to adults. Adverse environmental health conditions affect children more as these have negative effects not only on health but also on the development. Children are more prone to and more at risk than adults because of rapid skeletal growth, organ and tissues development, greater risk of hearing loss, greater need for food and rest, higher chemical absorption rates, smaller size and lower heat tolerance due to their physiological and immunological countenance; some additional factors also contribute to this. Documented reports show the impact on health viz. poverty related (e.g. Malnutrition, fatigue, anemia etc), psychological effects and distress of child labour, occupational cancers, neurotoxicity, injuries, exposures to adverse physical factors, skin ailments etc. A multi-disciplinary approach involving specialists from medical, toxicological, environmental, psychological and socio-anthropological fields shall produce integral information and, approach on various aspects of child development to prepare a better policy for child labour. India has the highest number of child workers, but unfortunately, there is hardly any research done or policies framed for their occupational safety and health. Hence there is an urgent need for intensive focus and research along with political and practical decisions to improve the conditions of working children for the betterment of their health and development.
\end{abstract}

\section{INTRODUCTION}

Child labour is a worldwide phenomenon but more focus is required on developing countries. The policy framework of International Labour Organization (ILO) to eliminate child labour is based on United Nations (UN) Declaration of Fundamental Principles and Rights at work (1998). Over 170 million children worldwide still work in order to sustain their basic needs. About 22000 working children die due to occupational hazards every year, as per ILO estimates. Indian population has more than 17.5 million working children in different industries (Child Labour in India 1994; Tiwari 2005), and maximum are in agricultural sector, leather industry, mining and match making industries etc. As per provisions in the Constitution of India, "the State shall direct its policy towards protection of childhood and youth against exploitation and they shall not be employed to work in any factory or mine or engaged in any hazardous employment"; but unfortunately India has the largest number of urban and rural child workers in the world (Fyfe, 1994).
Working children are from different age, race, income or health status groups. Some of the important aspects viz. short and long term effects of physical, mental and chemical work exposures and conditions on the health and development of child, the nature of work and its hazards and possible health effects, the situation in which children work etc. must be analyzed well. Anatomical, physiological and mental aspects in different socio-economic conditions are health components, which require urgent attention, particularly concerning growth and development, orthopaedic and musculo-skeletal disorders, poisoning, intoxication and premature deaths.

According to the estimates, there are more than 250 million working children between the ages of 5 and 14 in developing countries, and the majority of the child workers live in the developing countries of Asia, Africa and Latin America; but there are also pockets of child labor in many industrialized countries (Parker 1997; ILO 1998). Work, environmental and occupational conditions have a negative impact on health and development of the children (CHSICL 1998). Child labour is more harmful if it interferes with school, 
recreation and rest. Child labour Laws were implemented in US during American industrial era by the intervention of social workers like Samuel Gompers (labour leader), Sinclair Lewis (writer) and Lewis Hine (photographer) after decades of struggle. It is difficult to find good data about the impact of child labor on health to assess and evaluate its harmful aspects especially so in S.E. Asian countries. Some environmental epidemiologic studies and research on young workers suggest that children could have higher health risks than adults when exposed to some hazards. Moreover, several theoretical concerns about the impact of occupational exposures on child health still need to be studied.

\section{ENVIRONMENTAL AND OCCUPATIONAL CONDITIONS}

The majority of child labour is involved in dangerous or hazardous occupations such as agriculture, manufacture, construction, retail and marginal activities. Agriculture is the most common child occupation worldwide, and employs more working children than any other sector. This activity is consistently ranked among the most hazardous industry for mortality and morbidity (Cooper and Rothstein 1995; Landrigan et al. 1995; Wilk 1993). But, despite its hazards, agriculture is one of the less-regulated sectors and it is among the sectors where the existent laws are very difficult to enforce (Wilk 1993; Committee on the Health and Safety Implications of Child Labor 1998). Moreover, most farms are not family units anymore where the children are helping their parents with the daily chores and learning their future job. There is an international trend for the introduction of mechanization, specialization (monoculture) and technological advances in the fields. These processes are followed by the decrease in the numbers of farms, especially small family farms, a decrease in the numbers of workers employed with an increase in the size of the farms and in productivity. Thus, there are fewer children and adolescents of the farm owners working and higher number of adolescents hired as farm-workers or farmworkers' children; working alongside their parents in the fields. The children generally start to work at a very young age and usually work for long hours for little or no payment. They are exposed to dangerous farm machinery causing fatal and non-fatal injuries, while operating or working near them. Children are also exposed to strenuous labor, like carrying heavy loads and working in uncomfortable postures such as stooping in the same position or bending very frequently, which could affect the musculo-skeletal development of the children. Other hazards present in the fields are pesticides and the weather, especially the heat, which can be particularly dangerous for children. Poor field sanitation contributes by facilitating the transmission of communicable diseases, which is worsened by the pesticides and the heat. Migrant workers are particularly at risk since their housing conditions are frequently inappropriate (Bureau of International Labor Affairs 1998).

Manufacturing is another sector, but the types of industry vary widely from country to country. Most of these children are employed in small workshops or in home-based work. They seldom work in medium-size or large enterprises, but such establishments sometimes contribute indirectly to child labor by subcontracting out certain production tasks to small workshops and home-workers that make extensive use of child labor and generally are not covered by child labor laws (UNICEF 1997; Forastieri 1997; Bureau of International Labor Affairs 1998). Industry has specific hazards linked to each production process that are specific to the tasks performed, Along with some general hazards that arise not from the production process but from uncaring management. Examples of these problems are naked electric wires, lack of first-aid facilities, poor ventilation, lack of sanitation, lack of sufficient light, exposure to loud noise, proximity or operation of dangerous machines, and the lack of protective equipment. In some cases physical punishments are frequent (Bequele et al. 1995).

Specific hazards vary according to the industry type. Thus, child workers will be exposed to high temperatures, high risk of accidents caused by cuts and burns at the brassware and glass-bangle industry, to silica dust at the earthenware and porcelain factories, and to chemical hazards and risk of fire and explosion at the matches and firework workshops (UNICEF 1997; Forastieri 1997). Child workers are also exposed to important hazards in the export sector. In the carpet industry in India the children are exposed to repetitive movements, chemical hazards, inhalation of wool dust contaminated with biological agents and inadequate working postures. In the production of soccer balls in Pakistan, children are exposed to inadequate 
working postures, and in the shoe industry in Portugal, Italy and Brazil, children are exposed to glue (Forastieri 1997; Fyfe and Jankanish 1996).

Manufacturing is a very hazardous sector and the subcontracting practice is an issue of major concern. This practice discharges the mediumsized and large-enterprise industries of the hazardous activities, by out-sourcing this type of work to small workshops and home-based work that are frequently exempt from the existing legislation. Moreover, even if these establishments were covered by the law, they are much more difficult to monitor and have less economic capacity to work towards higher standards of occupational health and safety (Bureau of International Labor Affairs 1998). The construction sector is one of the most hazardous working environments with regard to the risk of accidents, especially for children. Despite this fact, this sector employs a considerable number of children in several parts of the world. In Brazil, four percent of the workers between the ages of 10 and 14 and eight percent of those between 15 and 17 work in the construction sector. In addition to the risk of accident, there are exposures to noise, silica, asbestos, harmful dust, heavy loads, etc. (Committee on the Health and Safety Implications of Child Labor 1998).

The service sector includes domestic services, child prostitution/ commercial sex workers, street workers, work for family etc. The informal and hidden nature of the domestic work makes it difficult to estimate the number of domestic workers around the world, but it is one of the most common forms of urban child labor in developing countries and employs mainly girls. In Brazil eight percent of the workers between the ages of 10 and 14 were domestic workers (Bureau of International Labor Affairs 1998). Workers often live at the workplace, are expected to work till odd hours of the day with few days off, and are deprived of attending school. Far from their own families, they are very vulnerable and can receive harsh treatment from their employers, sometimes suffering physical, mental, and sexual abuse. In some cases they lack an appropriate place to sleep and do not receive sufficient food. They usually receive low or no wage; bonded labor is very common in some places (UNICEF 1997).

Child prostitution has been defined as "the act of engaging or offering the services of a child to perform sexual acts for money or other consideration..." Generally children do not commit child prostitution but the adults who engage in prostitution or offer a child's sexual services to others force them. It is estimated that at least 1 million girls worldwide are lured or forced into this scandalous form of child exploitation. Child prostitution is more frequent in developing countries such as Brazil, Thailand where more than 200,000 children are exploited, but it can be found in developed countries such as the United States, which has more than 100,000 child prostitutes. Although girls are the most frequent targets, boys are also often exploited. There are documented cases of children as young as six or seven being exploited in Brazil. While this huge problem may be widely visible to childprostitution exploiters, it remains virtually invisible to the people who could help these children (UNICEF 1997; Bequele et al. 1995; Bureau of International Labor Affairs 1996). Commercial sexual exploitation frequently involves trafficking of children whether they are kidnapped or sold by their parents. The children are often recruited under the false pretense of marriage or a good job in the city. While the main media focus is sex tourism, it is important to keep in mind that local persons also exploit these children. But the new face of exploitation is transnational, with criminal networks that operate not only in neighboring countries but also across the globe (Bureau of International Labor Affairs 1998; Bureau of International Labor Affairs 1996; UNICEF 1997). Child prostitutes suffer extreme physical and mental abuse, making this form of exploitation one of the most hazardous. They also risk drug addiction, early and unwanted pregnancies, and HIV and other sexually transmitted diseases. (UNICEF, 1997; Bureau of International Labor Affairs, 1998). The process of rescue and rehabilitation for these children is very complicated. They are frequently prosecuted by the system that should be protecting them. Even if they manage to return to their homes, they often face stigma and rejection by their families and communities forcing them to a long life of drudgery (UNICEF 1997).

Urbanization is a basic factor behind street workers. Many of them are not street children in the strict sense since the majority of these street workers return home each night and provide critical financial support for their families (UNICEF 1997). These children polish shoes, wash and guard cars, carry luggage, sell goods at the traffic- 
light intersections and scavenge and pick up rags. They struggle to legitimize their work on the streets. Street workers are mainly exposed to street violence. Many are lured to drugs, prostitution and illegal work (thieving, trafficking drugs). They often need to defend their space on the street and can be prosecuted by the police (in Rio de Janeiro, Brazil, for example, three street children are killed every day, many by the police). They are also exposed to traffic accidents and extreme weather conditions and seldom attend school. Scavenging is an example of a very hazardous street work. It adversely affects the child's self-esteem; moreover, it is very unhygienic.

Working for their families, children can learn to participate in the household chores that can develop a sense of self-worth, but sometimes, working for the family is essential to enable the parents to work outside the home. This is a hidden form of exploitation that affects mainly girls and it is often not even considered work. In Brazil four percent of the children between the ages of 10 and 14 and nine percent of the children between 15 and 17 perform exclusively household activities without attending school. Work for the family can demand long hours, thus preventing the children from going to school or doing well in school, perpetuating the poverty cycle. It also includes some heavy chores as taking care of siblings and carrying heavy loads of firewood and buckets of water (UNICEF, 1997).

\section{BIOLOGICAL VULNERABILITY OF A CHILD}

Children are more vulnerable and susceptible than adults biologically due to many reasons. The brain of the child is not fully developed. The full number of neurons is reached at around two years of age and myelination of the brain is not completed until adolescence; exposure to certain toxins present in the workplace can hinder the process of maturation. The gastro-intestinal, endocrine and reproductive systems and renal function are immature at birth and mature during childhood and adolescence. Exposure to certain toxins present in the workplace can hinder the process of maturation, and the elimination of hazardous agents is less efficient. The enzyme system is immature in childhood, leading to less effective detoxification of hazardous substances. Most of the cells of the organs and tissues in children are smaller than in adults, therefore they have a larger surface area; absorption of toxin through the skin is higher than in adults. Children have higher metabolic rate and oxygen consumption and therefore a greater intake of air per unit body weight; The volume of air passing through the lungs of the resting infant is twice that of the resting adult (per unit body weight) over the same time period. The same applies to alveolar capillary absorption. This will slowly change during childhood and adolescence. This can lead to more respiratory absorption of toxins.

Children have greater energy consumption. An increased energy requirement for growth raises susceptibility to toxic (Forastieri 1997; Fyfe 1996). Sweat glands are not fully developed, and the thermo-regulatory system is not fully developed during childhood leading to increased sensitivity to heat and cold. Children have greater energy and fluid requirements per unit body weight than adults. The reason is that they lose more water per kilogram body weight through the lungs, due to the greater passage of air through them, through the skin (larger surface area) and through the kidneys (inability to concentrate urine). They are more likely to dehydrate. The area of a child's skin is 2.5 times greater than that of an adult (per unit body weight). Skin structure is only fully developed after puberty. This can lead to increased absorption through the skin. Children have thinner skin, again leading to an increased absorption through the skin. Metals are retained in the brain more readily in childhood than in adulthood and absorption is greater (lead and methyl mercury).

Additionally, children are psychologically immature, they have risk-taking behaviour, they are not experienced at work, nor are they trained on hazards or on safety; often there is inadequate supervision. Children want to perform well; they are willing to go the extra mile without realizing the impact of hazards. Additionally, children learn poor health and safety behaviour from adults, and in terms of organization and rights, they are virtually powerless.

Thus, children are susceptible to all of the dangerous exposures faced by adults when placed in the same environment. However, children differ biologically from adults in their anatomical, physiological, and psychological characteristics because of their process of growth and development. Thus, exposure hazards that affect adults can affect children much more strongly (Bequele et al. 1995; Forastieri 1997; ILO 
1998). The epidemiological evidences and the theoretical concerns for exposures that could be important to understand the dangerous impact for children must be given focus for concentration and intervention.

Children have a higher risk of injuries than adults. In a study in the United States, teens between 15 and 17 have an injury rate of 4.9 per $100 \%$ full time equivalent workers, while in the group of 16 years of age and older this rate was 2.8 (Committee on the Health and Safety Implications of Child Labor 1998). There is also evidence that heavy loads can be more dangerous for children the smaller they are. Parker et al. found that back injuries were more common in smaller workers than in larger workers (Parker et al. 1994). The other epidemiological evidence that highlights dangerous exposures for children come mainly from studies of young workers and from environmental studies. These studies show that children have higher susceptibility to lead, silica and benzene. Children are also more susceptible to noise, heat and ionizing radiation. (Bequele et al. 1995; Committee on the Health and Safety Implications of Child Labor 1998).

The inappropriate structure of work schedules (long hours, early/late hours with frequent changes) and the lack of supervision increase the risk of work-related injuries and illnesses. Developmental factors that could put teens at a higher risk than adults are also important to consider. Childhood and adolescence are periods of rapid growth in a young person's life; and thus, they could be at particularly high risk of injuring ligaments and damaging bone-growth plates. Although little research has been done on the long-term consequences of premature exposure to heavy work and to repetitive back-straining movements, ergonomic factors, nevertheless they remain a concern (Newton 1997). Expert panels have hypothesized that children are particularly vulnerable to potential carcinogens due to their rapid cell growth. There are concerns that chemical exposures could have adverse effects on normal hormonal development of adolescents, altering the delicate balance of hormones and their feedback loops. Chemical exposures could result in devastating effects, given the importance of the endocrine system during this life period. Some authors also believe that exposures to toxic chemicals at a very young age could alter the body's response to future toxin exposures (Forastieri 1997; Fyfe 1993). Rapid cell growth could strengthen the exposure effects, thus shortening the latency period of some diseases. Even in situations where it does not happen, children have longer periods of exposure to cumulative hazards (Forastieri 1997; Bequele et al. 1995).

Machines, tools, work furniture and personal protective equipment are not designed for children. Children using machines, tools and work furniture (seats, workbenches, etc.) designed for adults may develop musculoskeletal disorders such as chronic repetitive-strain injuries, repetitive-motion trauma, back problems, tenosynovitis, vibration-induced disorders and white-finger syndrome. They could also be at higher risk for injuries due to fatigue. Moreover, personal protective equipment frequently does not fit children. Thus, they often have to work without it or use alternative devices that do not provide real protection (Forastieri 1997; ILO 1997; ILC 1999). Since children respond differently than adults to physical and chemical exposures (Fassa et al. 1999; Bethancourt et al. 2002), the permissible exposure limits (PEL) established for adults might not be sufficiently protective for children. If they are allowed to work in places where these types of exposures exist, permissible exposure limits should be evaluated according to the child's age.

\section{CONCLUSION}

Working children are from different age, race, income or health-status groups. The nature of work, its hazards and possible health effects, the situation in which children work are important aspects with respect to predictive short and long term effects of physical, mental and chemical work exposure on the health development of child labours in social system. Anatomical, physiological and mental aspects in different socioeconomic conditions are health components that require urgent attention, particularly concerning growth and development, orthopaedic and musculosketal disorders, poisoning, intoxication and premature deaths. Children are more prone and at high risk than adults because of rapid skeletal growth, development of organ and tissues, greater risk of hearing loss, developing ability to assess risks, greater need for food and rest, higher chemical absorption rates, smaller size and lower heat tolerance due to their physiological and immunological aspects.

There are well documented reports that show 
the impact on health viz. poverty related (e.g. Malnutrition, fatigue, anemia etc.), psychological effects and distress of child labour, occupational cancers, neurotoxicity, injuries, exposure to adverse physical factors, skin ailments, Carpel Tunnel Syndrome (rapid trigger movement of fingers) etc. A multidisciplinary approach involving specialists with medical, toxicological, psychological and socio-anthropological knowledge and skills shall produce integral information on various aspects of child development. There is urgent need of intensive focus and research along with political and practical decisions to improve the conditions of working children. Government, workers, employers and the community must share the responsibility for controlling the special psychological risk factors that child face. The primary health care approach is better way to provide health care to working children. Considering the present situation, there is urgent need of social, political and technological intervention, good quality research, proper legislation and law, a comprehensive policy, which can be implement, for better planning and management of child labour issues, to improve the condition of working children.

\section{REFERENCES}

Bequele A, Myers WE 1995. First Things First in Child Labour: Eliminating Work Detrimental to Children. Geneva: International Labour Office.

Bethancourt Eijkemans, Varillas Hiba 2002. Report of Technical Workshop on Hazardous Child Labour. Geneva: International Labour Office.

Bureau of International Labor Affairs (BILA) 1998. By the Sweat and Toil of Children, Vol. 5: Efforts to Eliminate Child Labor. ILAB's Child Labor Series. Volume V. Washington, DC: U.S. Department of Labor.

Bureau of International Labor Affairs (BILA) 1996. Forced Labor: The Prostitution of Children. Washington, DC: U.S. Department of Labor.

Child Labour in India (CLI) 1994. Trading away the Future: Child Labour in India's Export Industries. International Labour Rights Education and Research Fund.

Newton MA 1997. Safe Work/Safe Workers: A Guide for
Teaching High School Students about Occupational Safety and Health. Children's Safety Network/ MA Dept of Public Health, Education Development Center, Inc.

Committee on the Health and Safety Implications of Child Labor (CHSICL) 1998. Protecting Youth at Work: Health, Safety, and Development of Working Children and Adolescents in the United States. Washington, DC: National Academy Press.

Cooper S, Rothstein M 1995. Health hazards among working children in Texas. South Med J, 88(5): 550554.

Fassa AG, Facchini LA, Agnol M 1999. Child Labor and Health: Problems and Perspectives, International Journal of Occupational and Environmental Health.

Forastieri V 1997. Children at Work: Health and Safety Risks. Geneva: International Labour Office.

Fyfe A, Jankanish M 1996. Trade Unions and Child Labor. ILO Child Labour Collection. Geneva: International Labour Office.

Fyfe A 1993. Child Labour: A Guide to Project Design. Geneva: International Labour Office.

Fyfe A 1994. Child Labour Policy and the Role of Education in India. Geneva: International Labour Organization (Unpublished Manuscript).

International Labour Organization (ILO) 1997. Child Labor: How the challenge is being met. International Labor Review, 136(2): 233-257.

International Labour Organization (ILO) 1998. Child Labour: Targeting the Intolerable. Geneva: International Labour Office.

International Labor Conference (ILC) 1999. Convention 182, Convention Concerning the Prohibition and Immediate Action for the Elimination of the Worst Forms of Child Labor. Geneva: International Labor Organization. Available at http://www.ilo.org/public/ english/10ilc/ilc87/com-chic.htm, Geneva: International Labor Organization.

Landrigan P, Pollack S, Belville R, Godbold J 1995. Child Labor. Pediatr Ann, 24 (12): 657-662.

Parker D. Child Labor 1997. The impact of economic exploitation on the health and welfare of children. Minnesota Medicine, 80(7):10-13-52-55.

Parker DL, Carl WR, French LR, Martin FB 1994. Characteristics of adolescent work injuries reported to the Minnesota Department of Labor and Industry. Am J Public Health, 84(4): 606-611.

Tiwari RR 2005. Child labour in footwear industry: Possible occupational health hazards. Indian J Occup Environ Med, 9: 7-9.

UNICEF 1997 The State of the Worlds Children 1997. Oxford: Oxford University Press.

Wilk V 1993. Health hazards to children in agriculture. Am J Ind Med, 24(3): 283-90. 